\title{
Mechanism for epigenetic variegation of gene expression at yeast telomeric heterochromatin
}

\author{
Tasuku Kitada, ${ }^{1,2}$ Benjamin G. Kuryan, ${ }^{1,2}$ Nancy Nga Huynh Tran, ${ }^{1,2}$ Chunying Song, ${ }^{1,2}$ Yong Xue, ${ }^{1,2}$ \\ Michael Carey, ${ }^{1,2}$ and Michael Grunstein ${ }^{1,2,3}$ \\ ${ }^{1}$ Department of Biological Chemistry, David Geffen School of Medicine, ${ }^{2}$ the Molecular Biology Institute, University of \\ California at Los Angeles, Los Angeles, California 90095, USA
}

\begin{abstract}
Yeast contains heterochromatin at telomeres and the silent mating-type loci (HML/HMR). Genes positioned within the telomeric heterochromatin of Saccharomyces cerevisiae switch stochastically between epigenetically bistable ON and OFF expression states. Important aspects of the mechanism of variegated gene expression, including the chromatin structure of the natural $\mathrm{ON}$ state and the mechanism by which it is maintained, are unknown. To address this issue, we developed approaches to select cells in the ON and OFF states. We found by chromatin immunoprecipitation (ChIP) that natural ON telomeres are associated with Rap1 binding and, surprisingly, also contain known characteristics of OFF telomeres, including significant amounts of Sir3 and H4K16 deacetylated nucleosomes. Moreover, we found that H3K79 methylation (H3K79me), H3K4me, and H3K36me, which are depleted from OFF telomeres, are enriched at $\mathrm{ON}$ telomeres. We demonstrate in vitro that H3K79me, but not H3K4me or H3K36me, disrupts transcriptional silencing. Importantly, H3K79me does not significantly reduce Sir complex binding in vivo or in vitro. Finally, we show that maintenance of H3K79me at ON telomeres is dependent on transcription. Therefore, although Sir proteins are required for silencing, we propose that epigenetic variegation of telomeric gene expression is due to the bistable enrichment/depletion of H3K79me and not the fluctuation in the amount of Sir protein binding to nucleosomes.
\end{abstract}

[Keywords: epigenetics; position effect variegation; silencing; telomeres; histones; Sir complex]

Supplemental material is available for this article.

Received July 13, 2012; revised version accepted September 7, 2012.

Epigenetics is traditionally defined as "the study of mitotically and/or meiotically heritable changes in gene function that cannot be explained by changes in DNA sequence" (Riggs et al. 1996). Position effect variegation (PEV), discovered in the fruit fly Drosophila melanogaster, is a classic example of an epigenetic phenomenon (Girton and Johansen 2008). PEV is characterized by the reversible and stochastic switching of a gene positioned within heterochromatin between ON and OFF states. Telomere position effect (TPE), at the heterochromatin of telomeres in budding yeast, is a form of PEV (Supplemental Fig. S1; Gottschling et al. 1990; Mondoux and Zakian 2006). TPE involves the variegated expression of genes positioned near telomeres at the boundary of heterochromatin and euchromatin. Although TPE in yeast was discovered more than two decades ago (Gottschling et al. 1990), how the variegated gene expression pattern arises at telomeres

${ }^{3}$ Corresponding author

E-mail mg@mbi.ucla.edu

Article is online at http://www.genesdev.org/cgi/doi/10.1101/gad.201095.112. is still poorly understood (Ptashne 2002; Mondoux and Zakian 2006; Madhani 2007).

The formation of telomeric and silent mating-type locus heterochromatin has been well characterized, and current data are consistent with a model in which yeast heterochromatin proteins assemble and spread along histones in a stepwise manner (Hecht et al. 1996; Rusche et al. 2003; Mondoux and Zakian 2006). In this process, Rap1 bound at the telomeric $\mathrm{TG}_{1-3}$ repeats (Buchman et al. 1988; Klein et al. 1992) recruits Sir4 through direct protein-protein interaction (Moretti et al. 1994; Hoppe et al. 2002; Luo et al. 2002). Sir4 in turn recruits Sir2 (Moazed et al. 1997; Strahl-Bolsinger et al. 1997), an NAD-dependent histone deacetylase (HDAC) with specificity for histone H4K16 acetylation (H4K16ac) (Imai et al. 2000; Landry et al. 2000; Smith et al. 2000). Deacetylation of H4K16ac generates a high-affinity binding site for the Sir3 protein (Johnson et al. 1990; Liou et al. 2005), which in turn recruits more Sir4 and Sir2 (Hecht et al. 1996; Hoppe et al. 2002; Luo et al. 2002). Cycles of H4K16 deacetylation and Sir3 recruitment enable spreading of 
the Sir complex along telomeric heterochromatin. The spreading of the Sir complex is eventually blocked by H4K16ac in adjacent euchromatin by the histone acetyltransferase Sas2 (Kimura et al. 2002; Suka et al. 2002). Sas2-mediated acetylation of H4K16 is also thought to enhance the incorporation of the histone $\mathrm{H} 2 \mathrm{~A}$ variant Htz1/H2AZ (Shia et al. 2006), which may act as an additional barrier to Sir complex spreading (Meneghini et al. 2003).

Similarly, H3K4 methylation (H3K4me), H3K36me, and $\mathrm{H} 3 \mathrm{~K} 79 \mathrm{me}$ have also been proposed to contribute to the boundary between heterochromatin and euchromatin, but the exact role that each modification plays in this process is less well defined (Verzijlbergen et al. 2009). It has been suggested, using histone point mutant and methyltransferase deletion strains, that the presence of H3K4me or H3K36me prevents ectopic binding of Sir proteins in euchromatin (Santos-Rosa et al. 2004; Tompa and Madhani 2007). More critically, the overexpression of the H3K79 methyltransferase Dot1 has been shown to disrupt gene silencing in vivo, and it has been proposed that H3K79me may block Sir complex binding to antagonize subtelomeric silencing in vivo (Singer et al. 1998; van Leeuwen et al. 2002; Ng et al. 2003; Katan-Khaykovich and Struhl 2005; Altaf et al. 2007; Fingerman et al. 2007; Onishi et al. 2007). Genetic, biochemical, and structural studies have shown that unmethylated H3K79 is a contact site for Sir3 and that methylation of H3K79 can disrupt that interaction between the H3K 79 region and Sir3 in vitro (Ng et al. 2002; Altaf et al. 2007; Fingerman et al. 2007; Johnson et al. 2009; Martino et al. 2009; Armache et al. 2011; Ehrentraut et al. 2011). Moreover, removal of H3K79me has been shown to facilitate de novo establishment of silencing at the silent mating-type locus $H M L$ (Osborne et al. 2009). Although it has been reported that $\mathrm{H} 3 \mathrm{~K} 79$ methylation by Dot1 does not play a role in natural silencing at $H M L$ or at most subtelomeres (Takahashi et al. 2011), the study asked whether the genome-wide depletion of H3K79me would derepress heterochromatin silencing instead of directly addressing the function of $\mathrm{H} 3 \mathrm{~K} 79 \mathrm{me}$ at heterochromatin per se.

The precise mechanism by which heterochromatin prevents the transcription of a gene is not known. However, it has been proposed that the Sir complex can prevent gene activation by either blocking the assembly of the preinitiation complex (PIC; general transcription factors and RNA polymerase II [RNAPII]) or regulating the transition between transcription initiation and RNAPII elongation (Sekinger and Gross 2001; Chen and Widom 2005; Gao and Gross 2008). Additionally, it has been shown that the abnormal lengthening of telomeres can increase the strength of gene silencing (Kyrion et al. 1993; Li and Lustig 1996; Mishra and Shore 1999; Park and Lustig 2000).

In contrast to the formation of the OFF state of telomeric heterochromatin, the chromatin structure of the natural ON state has not been well characterized. Potentially, the natural ON state could result from the absence of Rap1 binding to telomeric repeats or loss of interaction between the Sir complex and nucleosomes due to H4K16ac or H3K79me (Ng et al. 2003; Moazed 2011). However, this is not necessarily the case, as it has been shown that a telomeric gene can be derepressed in the presence of Sir complex binding in an H4K16R Sir2-345 catalytic mutant strain (Yang et al. 2008), an H3K56 mutant strain (Xu et al. 2007), an H3 4-30 tail deletion mutant strain (Sperling and Grunstein 2009), and a strain with a Gal4Sirl fusion protein artificially recruited to a synthetic $H M R$ silent mating-type locus prior to the establishment of silencing (Kirchmaier and Rine 2006).

Therefore, to decipher the basis of epigenetic variegation, we sought to identify the molecular factors that determine the natural ON state of budding yeast TPE. To accomplish this, we first developed a method for isolating populations of cells with telomeres in the ON and OFF states. This approach is conceptually different from most previous studies in which mixed populations of cells with $\mathrm{ON}$ and OFF telomeres were compared with heterochromatin mutant strains with telomeres that are artificially ON (Rusche et al. 2003). We then assessed the structural differences in chromatin at the ON and OFF telomeres in vivo. Additionally, by in vitro reconstitution of heterochromatin, we asked whether any of the differences observed in vivo were sufficient to disrupt gene silencing using yeast nuclear extracts. Surprisingly, we found that Rap1 binding, Sir complex binding to nucleosomes, and H4K16 deacetylation were largely similar between the $\mathrm{ON}$ and OFF states in vivo. Instead, we demonstrate that H3K79me enables the disruption of gene silencing and inheritance of the natural ON state of the telomere by a transcription-mediated positive feedback loop despite the spreading of the Sir complex along nucleosomes. We conclude that H3K79me and not the difference in the amount of Sir complex binding to nucleosomes per se is the epigenetic basis for variegation at telomeres.

\section{Results}

\section{Isolation of $\mathrm{ON}$ and OFF cells by medium selection}

To determine the differences between the ON and OFF chromatin states, it was necessary to separate ON and OFF cells in bulk. To accomplish this, we employed a yeast strain harboring a $U R A 3$ reporter gene at a telomere at the left arm of chromosome VII (TEL07L). We isolated $\mathrm{ON}$ and OFF cells, respectively, by culturing the strain in medium lacking uracil (SD-ura) or medium containing the drug 5-FOA (SD+FOA), which is toxic to cells with Ura3 activity (Fig. 1A; Boeke et al. 1987). For comparison, YFR057W, a native gene located near a different telomere (native TEL06R), was monitored as a control.

A recent study had shown that the URA3-FOA assay may identify false positive hits when used in screens for detecting silencing mutants, making it necessary to confirm the expression of URA3 using quantitative RTPCR (qRT-PCR) (Rossmann et al. 2011). As shown in Figure $1 \mathrm{~B}$, the mRNA level of URA3 was low in cells cultured in SD+FOA and high in SD-ura when measured by qRT-PCR. In fact, the URA3 expression level of cells grown in SD-ura was comparable with that of a $\Delta$ sir3 
A
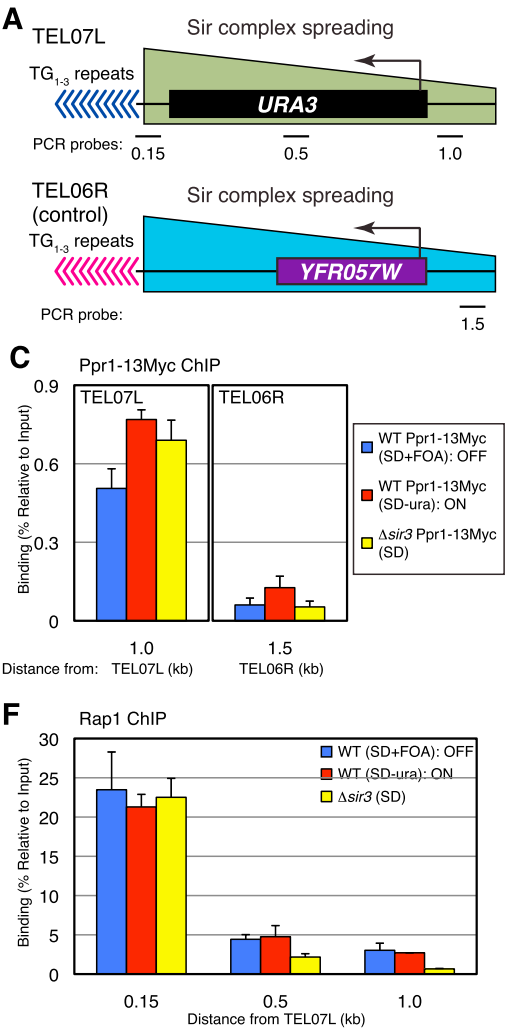
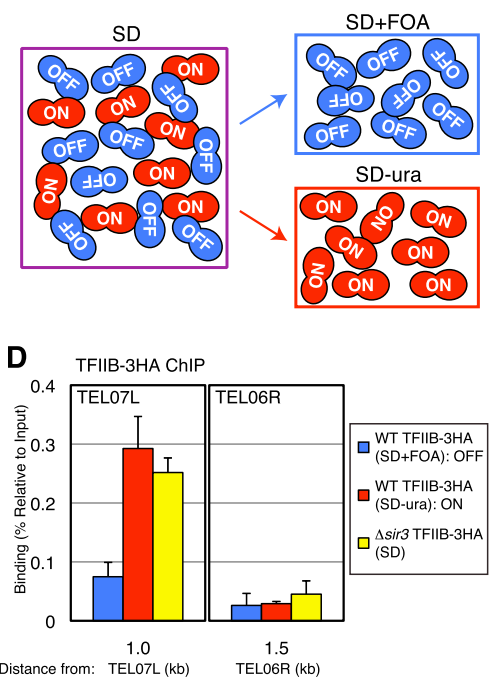

G

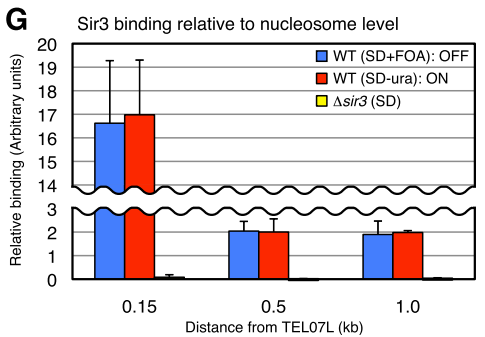

B

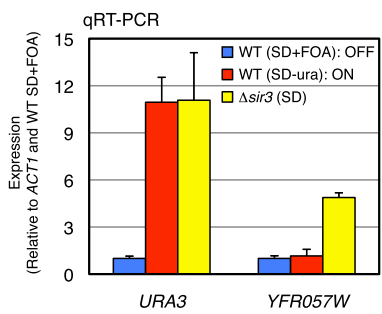

E RNAPII ChIP

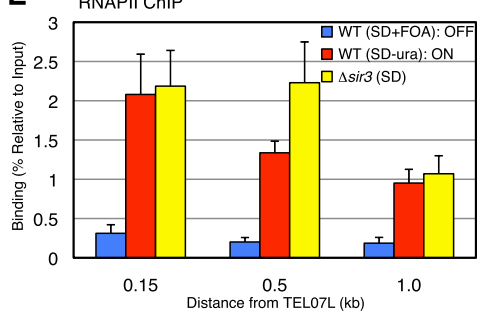

H

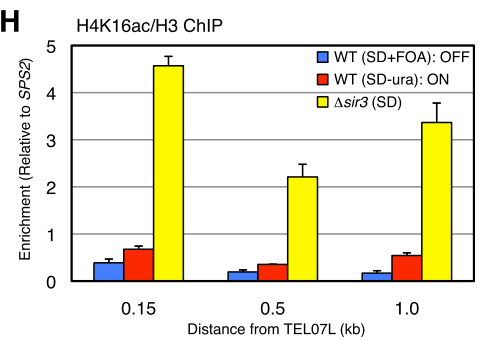

Figure 1. Rap1 binding to DNA and Sir protein binding to nucleosomes are not different between ON and OFF telomeres. $(A)$ Schematic of the medium selection approach to isolate ON and OFF telomeres. Probes were $\sim 0.15,0.5$, and $1.0 \mathrm{~kb}$ away from the telomeric repeats of URA3-TEL07L and $\sim 1.5 \mathrm{~kb}$ from native TEL06R. (B) qRT-PCR of URA3 at TEL07L and YFR057W at native TEL06R in wild-type (WT) SIR3 cells grown in SD+FOA (blue bars) and SD-ura (red bars) and $\Delta$ sir3 cells grown is SD (yellow bars). Data are presented as mean \pm standard deviation $(\mathrm{SD}) .(C, D)$ ChIP of Pprl-13Myc $(C)$ and TFIIB-3HA $(D)$ depicted as in $B$ except Pprl and TFIIB were tagged with 13Myc and 3HA, respectively. $(E-H)$ ChIP of RNAPII $(E)$, Rap1 $(F)$, Sir3 binding relative to nucleosome level $(G)$, and $\mathrm{H} 4 \mathrm{~K} 16 \mathrm{ac} / \mathrm{H} 3(H)$ at $U R A 3-T E L 07 \mathrm{~L}$ depicted as in $B$.

control strain in which heterochromatin is completely disrupted (Fig. 1B; Strahl-Bolsinger et al. 1997). Therefore, by the direct measurement of URA3 mRNA using qRTPCR, we found that our medium-based selection approach is capable of separating ON and OFF cells in bulk.

\section{TPE is regulated at the RNAPII PIC assembly step}

Previous studies had reported, in a contradictory manner, that heterochromatin prevents transcription by blocking either PIC assembly (Chen and Widom 2005) or the transition between initiation of transcription and RNAPII elongation (Sekinger and Gross 2001; Gao and Gross 2008). Therefore, we wished to clarify which step of the transcription process differed in our wild-type ON and OFF cells separated by medium selection. To accomplish this, we measured the binding of the URA3 activator Ppr1 (Myc-tagged), general transcription factor TFIIB (HAtagged), and RNAPII at URA3-TEL07L by chromatin immunoprecipitation (ChIP) in ON cells, OFF cells, and $\Delta$ sir3 cells as a control. RNAPII and TFIIB are known to characterize PICs during gene activation (Hahn 2004; Kostrewa et al. 2009). As shown in Figure 1C, Ppr1 was enriched at the promoter of $U R A 3$ at a similar level in the
ON and OFF states. In contrast, binding of TFIIB and RNAPII was observed at the ON but not OFF telomere (Fig. 1D,E). Thus, based on these results from our medium-selected $\mathrm{ON}$ and OFF cells, heterochromatin is permissive to activator binding but not PIC assembly. We conclude that the epigenetic variegation states of TPE are modulated at the PIC assembly step.

Histone methylation but not binding of heterochromatin proteins differentiates the ON and OFF telomeres

Differences in any of the steps of the heterochromatin assembly process could potentially explain how bistable $\mathrm{ON}$ and OFF chromatin states could exist at telomeres in wild-type yeast strains. To determine whether TPE can be explained by differences in the binding of key heterochromatin proteins, we measured the enrichment level of Rap1 and Sir3 at URA3-TEL07L in the medium-selected $\mathrm{ON}$ and OFF cells by ChIP. As shown in Figure 1F, binding of Rap1 to the ON and OFF telomeres was nearly identical. Similarly, and in contrast to previous models $(\mathrm{Ng}$ et al. 2003; Moazed 2011), we also observed that the level of Sir3 binding to nucleosomes along the subtelomeric 
region in the ON and OFF cells was essentially the same (Fig. 1G). Importantly, our measurements took into account the fact that the number of nucleosomes was expectedly reduced at $\mathrm{ON}$ telomeres compared with those that were OFF (Supplemental Fig. S2; Pokholok et al. 2005). Nevertheless, our data support the idea that epigenetic variegation at telomeres cannot simply be explained by Rap1 binding or the extent of Sir3 binding to nucleosomes.

Since binding of Rap1 and Sir3 was similar between the ON and OFF telomeres, we next asked instead whether chromatin modifications antagonistic to silencing could be differentially enriched at these telomeres. To accomplish this, we performed ChIP at URA3-TEL07L in ON and OFF cells using antibodies specific to various chromatin modifications, including H4K16ac, H3K4me, H3K36me, and H3K79me. As expected from the efficient binding of Sir3, we found that H4K16, a key histone residue that regulates Sir3 spreading, was strongly hypoacetylated at both ON and OFF telomeres compared with $\Delta$ sir3 (Fig. 1 H; Supplemental Fig. S2). However, in contrast, we found that histone methylation was differentially enriched between the ON and OFF telomeres. Specifically, H3K79 monomethylation (H3K79me1), H3K79 dimethylation (H3K79me2), H3K4 trimethylation (H3K4me3), and H3K36me3 were enriched at the ON telomere (Fig. 2; Supplemental Fig. S2). We note that the enrichment levels of Htz1/H2AZ, H3K56ac, and H3K79me3, which are also capable of affecting gene silencing (Meneghini et al. 2003; Xu et al. 2007; Frederiks et al. 2008), were not obviously different between ON and OFF telomeres (Supplemental Fig. S2). The ChIP results for all of the above at the native TEL06R control locus are shown in Supplemental Figure S3. Therefore, our results argue that histone $\mathrm{H} 3$ methylation is enriched at $\mathrm{ON}$ telomeres and has the potential to disrupt gene silencing without affecting the amount of Sir3 binding to nucleosomes.
Sir proteins and RNAPII co-occupy chromatin in the ON state

As shown above, binding of the heterochromatin proteins Rap1 and Sir3 was similar between the ON and OFF telomeres. However, a ChIP assay measures the average level of protein binding or enrichment of a modification in a population of cells. Therefore, it was unclear whether the chromatin fragments with RNAPII binding that are responsible for gene activity were the same as those bound by heterochromatin proteins. To address this problem, we used sequential ChIP to determine whether RNAPII-bound telomere chromatin fragments were cooccupied by Rap1 or Sir3. The ON telomere fragments were first isolated by immunoprecipitation of Flag-tagged RNAPII using a Flag antibody, after which binding of Rap1 or Sir3 was measured by sequential ChIP (Fig. 3A). As shown in Figure 3B, RNAPII binding was low in wildtype SIR3 but high in $\Delta$ sir3 control cells, as expected. Control sequential ChIP reactions with an RNAPII antibody or no antibody confirmed that RNAPII-bound chromatin fragments were enriched during the initial RNAPIIFlag ChIP (Fig. 3C,D). Importantly, sequential ChIP of Rap1 and $\operatorname{Sir} 3$ showed that these two proteins were indeed bound to the ON telomere (Fig. 3E,F). Furthermore, consistent with our ChIP experiments above using medium selection, we found that $\mathrm{H} 3 \mathrm{~K} 79 \mathrm{me} 1$ and $\mathrm{H} 3 \mathrm{~K} 79 \mathrm{me} 2$ are also enriched at $\mathrm{ON}$ telomeres (Fig. 3G,H; Supplemental Fig. S4). We conclude that RNAPII binding in the ON state is compatible with Rap1 or Sir3 binding.

\section{Fluorescence-activated cell sorting (FACS)-ChIP verification of the ON and OFF states}

The sequential ChIP experiment described above showed that RNAPII and Rap1, Sir3, or H3K79me co-occupied the same chromatin fragments in the natural ON state of TPE. To further confirm this result and rule out the possibility that the medium-selection approach was
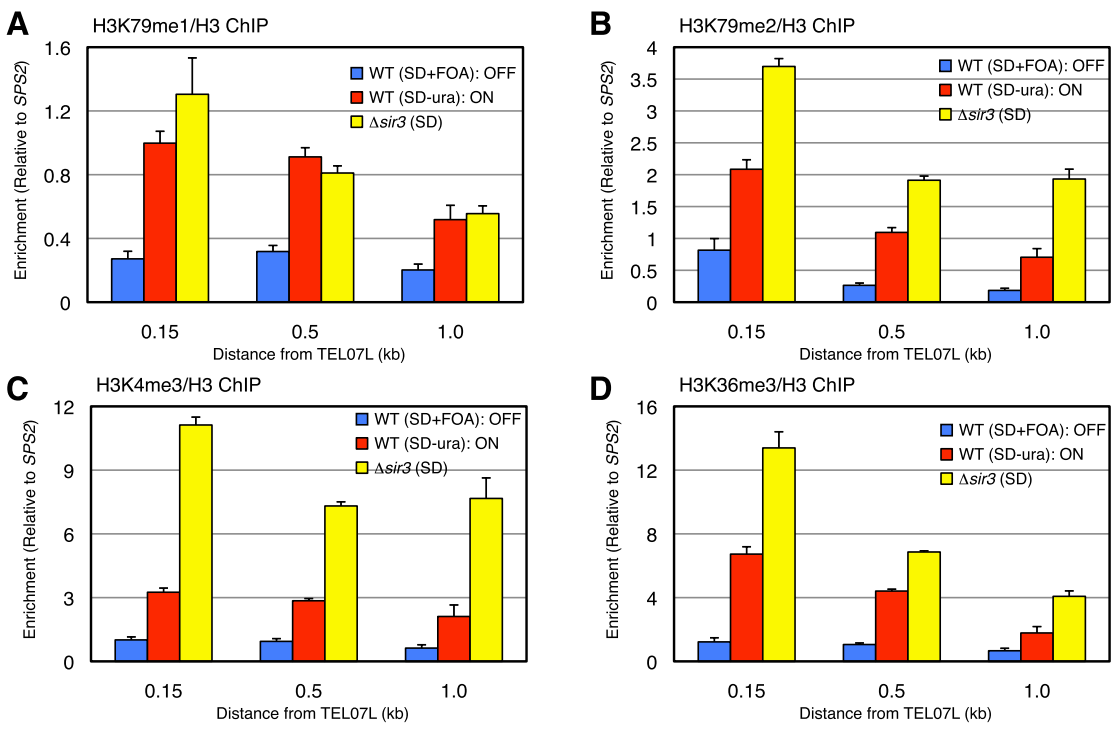

Figure 2. Histone methylation is enriched at $\mathrm{ON}$ telomeres. $(A-D) \mathrm{ChIP}$ of $\mathrm{H} 3 \mathrm{~K} 79 \mathrm{mel} /$ $\mathrm{H} 3(A), \mathrm{H} 3 \mathrm{~K} 79 \mathrm{me} 2 / \mathrm{H} 3(B), \mathrm{H} 3 \mathrm{~K} 4 \mathrm{me} 3 / \mathrm{H} 3(C)$, and $\mathrm{H} 3 \mathrm{~K} 36 \mathrm{me} 3 / \mathrm{H} 3(D)$ at URA3-TEL07L depicted as in Figure 1B. 
A

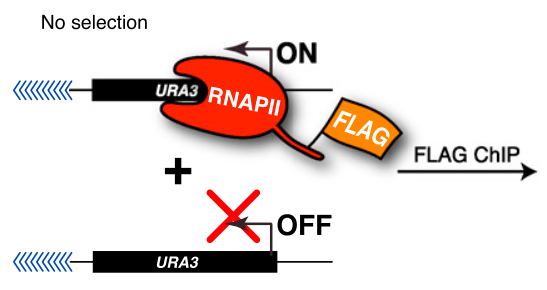

C

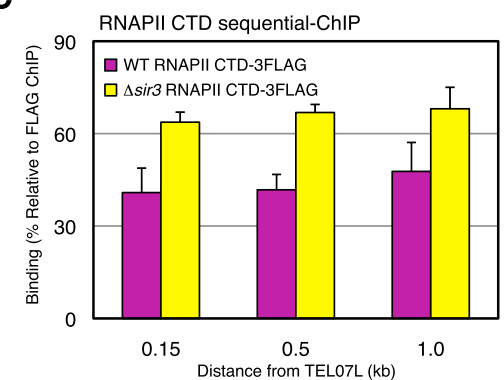

F

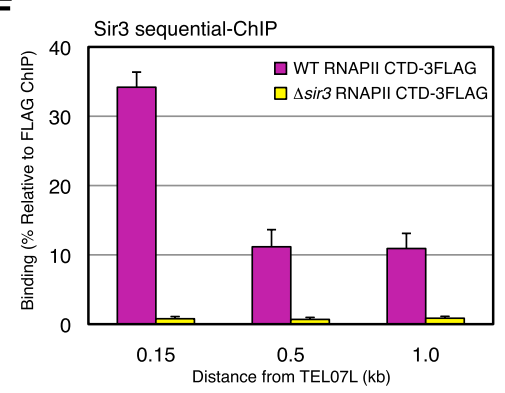

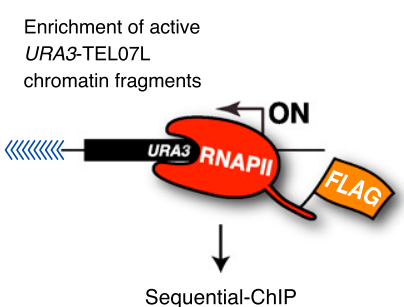

D

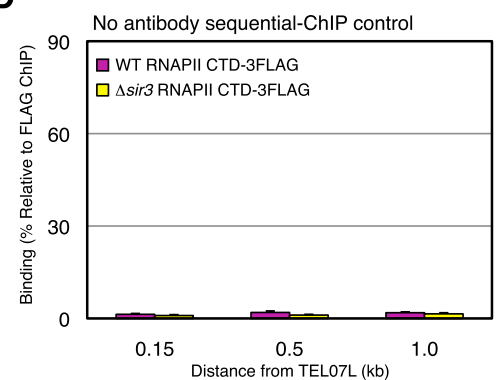

G

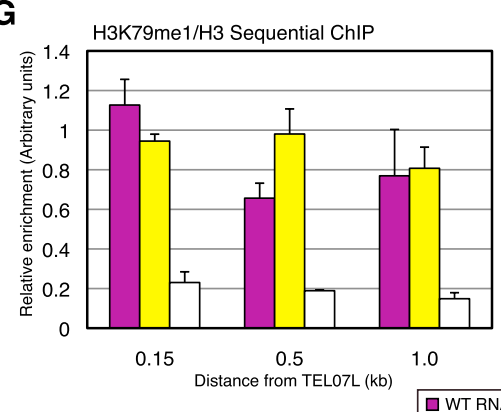

B

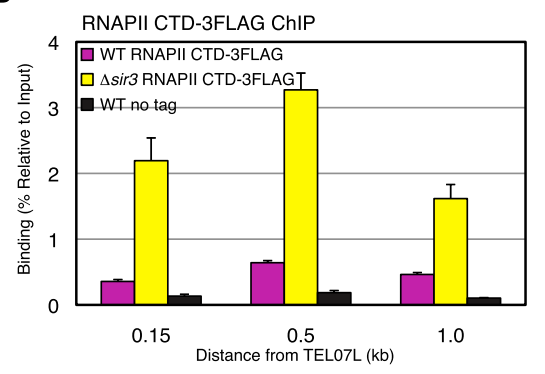

E

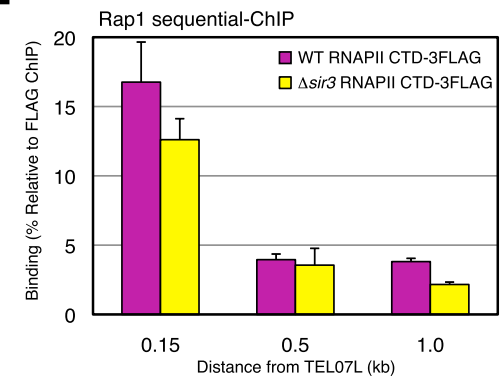

H

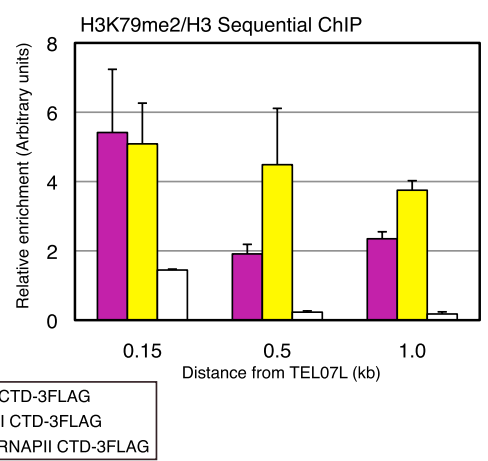

Figure 3. RNAPII-3Flag sequential ChIP assay confirms the co-occupancy of RNAPII and Rap1, Sir3, or H3K79me. (A) Schematic of the sequential ChIP approach to isolate ON telomeres. Rpb1, the subunit of the RNAPII complex containing the regulatory C-terminal domain (CTD), was C-terminally tagged with three tandem repeats of the Flag sequence and cultured in nonselective medium (YPD). ChIP was performed using an anti-Flag antibody to isolate chromatin fragments with RNAPII binding, including telomere fragments in the ON state. Probes were as in Figure 1A. (B) ChIP of RNAPII CTD-3Flag at URA3-TEL07L in wild-type (WT) SIR3 RNAPII CTD-3Flag (purple bars) and $\Delta$ sir3 RNAPII CTD-3Flag (yellow bars) cells grown in nonselective medium (YPD). A wild-type SIR3 strain without a 3Flag tag (black bars) was used as a negative control. Data are presented as mean \pm SD. $(C-F)$ Sequential ChIP of RNAPII (C), Rap1 $(E)$, and Sir3 $(F)$ at URA3-TEL07L depicted as in $B .(D)$ A mock sequential ChIP without an antibody was performed as a negative control. $(G, H)$ Sequential ChIP of H3K79me1/H3 $(G)$ and H3K79me2/H3 $(H)$ at URA3-TEL07L, depicted as in $C-F$ with the addition of $\Delta$ sir3 $\Delta$ dot1 RNAPII CTD-3Flag (white bars), which was used as a control strain that lacks H3K79me.

causing an unexpected artifact, we wished to separate ON and OFF cells by FACS and compare the chromatin states of the ON and OFF telomeres using ChIP. To perform FACS-ChIP, we constructed a strain with a URA3-GFP fusion gene inserted at TEL07L (Fig. 4A). An octa-glycine (G8) linker was inserted between Ura3 and GFP so that GFP would not interfere with Ura3 function (Sabourin et al. 2007). To make the level of the GFP protein more accurately reflect the real-time expression state of the URA3-GFP gene, the half-life of Ura3-G8-GFP was reduced by attaching the Cln2 PEST domain (PD), a protein degradation sequence, to the $\mathrm{C}$ terminus of GFP (Xu et al. 2006). Last, to facilitate the visualization of Ura3-G8-GFP-PD, the fusion protein was concentrated in the nucleus using a nuclear localization signal (NLS). The variegated gene expression pattern of URA3-GFP in this strain was confirmed by fluorescence microscopy in preFACS cells (Fig. 4B). For FACS, exponentially growing cells were fixed using formaldehyde, and GFP-positive and GFP-negative cells were separated and confirmed by microscopy and qRT-PCR (Fig. 4C,D). Approximately 1 million sorted cells were used for ChIP analysis per protein or histone modification tested. As shown in Figure 4E, Rap1 bound well at URA3-GFP-TEL07L in both ON and OFF cells. Importantly, we observed a significant amount of Sir3 binding in the ON cells as well as the OFF cells (Fig. 4F). The slight drop in the absolute level of Sir3 binding at the ON telomere was likely due to 
Kitada et al.

A

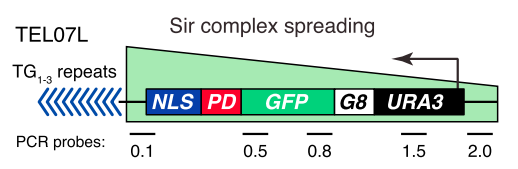

B Pre-FACS

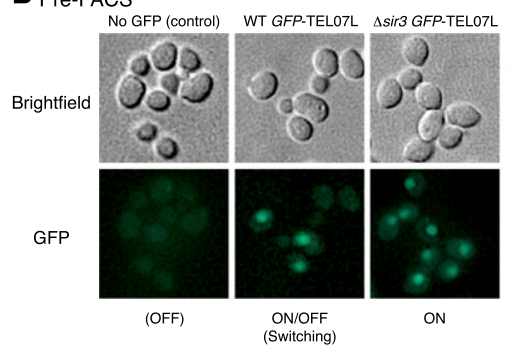

$\mathbf{F}$

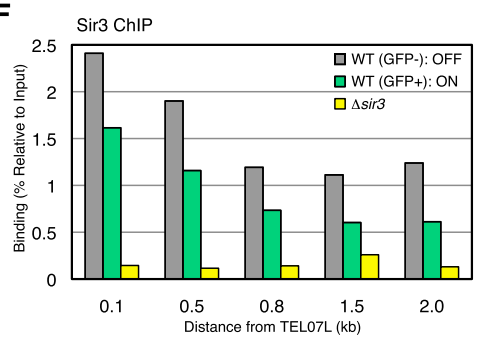

GFP- / GFP+

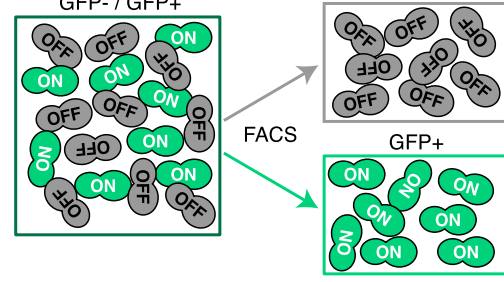

C Post-FACS

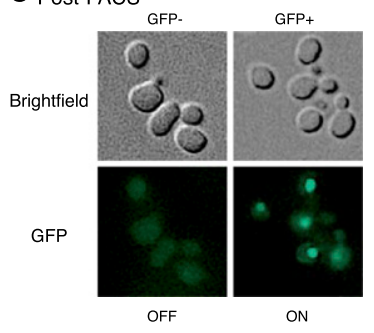

G H3K79me1 ChIP H

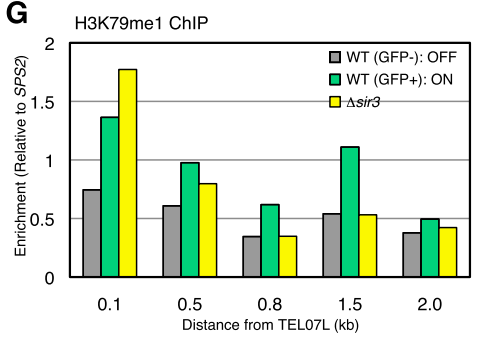

D

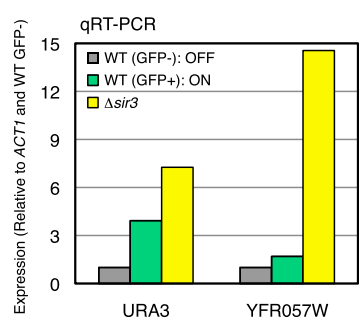

E
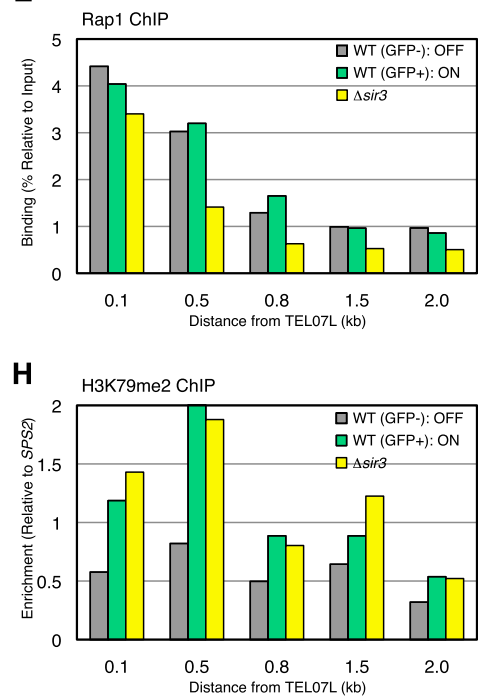

I ChIP

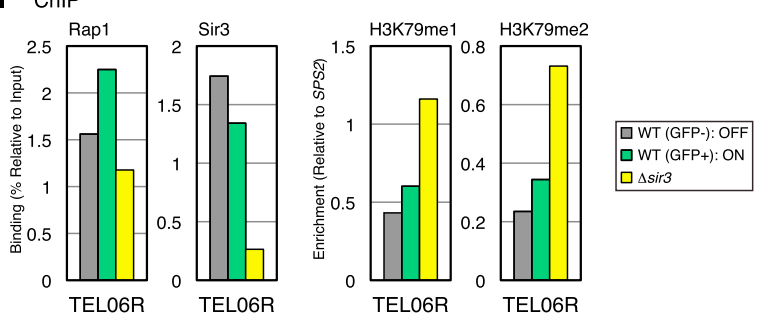

Figure 4. FACS-ChIP of URA3-GFP-TEL07L confirms that the ON and OFF states are differentiated by H3K79me. (A) Schematic of the FACS approach to isolate ON and OFF cells. URA3 regulated under its native promoter was fused to a G8 linker followed by yeastenhanced GFP1, a CLN2 PD, and a NLS from SV40. Probes were $\sim 0.1,0.5,0.8,1.5$, and $2.0 \mathrm{~kb}$ away from the telomeric repeats of URA3-G8-GFP-PD-NLS-TEL07L. $(B, C)$ Representative bright-field and fluorescence images of wild-type (WT) SIR3 and $\Delta$ sir3 cells with URA3-G8-GFP-PD-NLS-TEL07L along with wild-type SIR3 cells with native TEL07L lacking GFP (negative control) before FACS (B), and $\mathrm{GFP}^{-}$and $\mathrm{GFP}^{+}$wild-type SIR3 URA3-G8-GFP-PD-NLS-TEL07L cells after FACS $(C)$. (D) qRT-PCR of URA3 at TEL07L and YFR057W at native TEL06R in wild-type SIR3 GFP (gray bars) and $\mathrm{GFP}^{+}$(green bars) cells and $\Delta$ sir3 cells (yellow bars) grown in SD. Data are a representative result of three biological replicates. $(E-H)$ ChIP of Rap1 $(E)$, Sir3 $(F)$, H3K79me1 $(G)$, and H3K79me2 $(H)$ at URA3-G8-GFP-PD-NLS-TEL07L, depicted as in D. (I) ChIP of Rap1, Sir3, H3K79me1, and H3K79me2 at native TEL06R using a probe $\sim 0.5 \mathrm{~kb}$ away from the telomeric repeats, depicted as in $D$.

the expected decrease in nucleosome density of a transcriptionally active locus, similar to the ChIP results observed in the medium-selected cells (Supplemental Fig. S2). Finally, H3K79me1 and H3K79me2 were enriched at the ON telomere compared with OFF (Fig. $4 \mathrm{G}, \mathrm{H})$. As controls, the binding of Rap1 and Sir3 and the enrichment of H3K79me1 and H3K79me2 at native TEL06R, which lacks integrated URA3, are shown in Figure $4 \mathrm{I}$. We found very little change in any of these components at native TEL06R in the URA3 ON and OFF cells. Therefore, our FACS-ChIP data are consistent with the medium selection ChIP results above showing that Rap1, Sir3, H3K79me1, and H3K79me2 are enriched at the ON telomere of URA3-TELO7L.

\section{H3K79me disrupts gene silencing without affecting Sir complex binding in vitro}

The methylation of histones has previously been implicated in disrupting gene silencing (van Leeuwen et al. 2002; Santos-Rosa et al. 2004; Altaf et al. 2007; Fingerman et al. 2007; Onishi et al. 2007; Tompa and Madhani 2007; 
Martino et al. 2009; Verzijlbergen et al. 2009). However, since histone methylation, particularly H3K4me and H3K36me, generally correlates with transcription in yeast (Millar and Grunstein 2006), it was possible that the enrichment of some of these methylation marks was merely a consequence of, rather than the cause for, the ON state of TPE. Therefore, we sought to distinguish the function of these modifications and test directly whether they would be sufficient to disrupt Sir complex-mediated silencing using a yeast in vitro transcription (IVT) system (Fig. 5A,B).
In this system, we used a DNA template containing Gal4 DNA-binding sites and a TATA box (Fig. 5; Tantin et al. 1996). This template was previously shown to be highly responsive to activator GAL4-VP16 derivatives in a yeast nuclear extract (Ohashi et al. 1994). We assembled the template into chromatin using either unmodified histone octamers or octamers containing H3K4me3, H3K36me3, or H3K79me2. Methylated histones were generated using the methyl-lysine analog (MLA) technique (Simon et al. 2007) and validated by Western blot (Fig. 5C) and mass spectrometry (data not shown). GAL4-VP16
A Sir complex mediated in vitro silencing
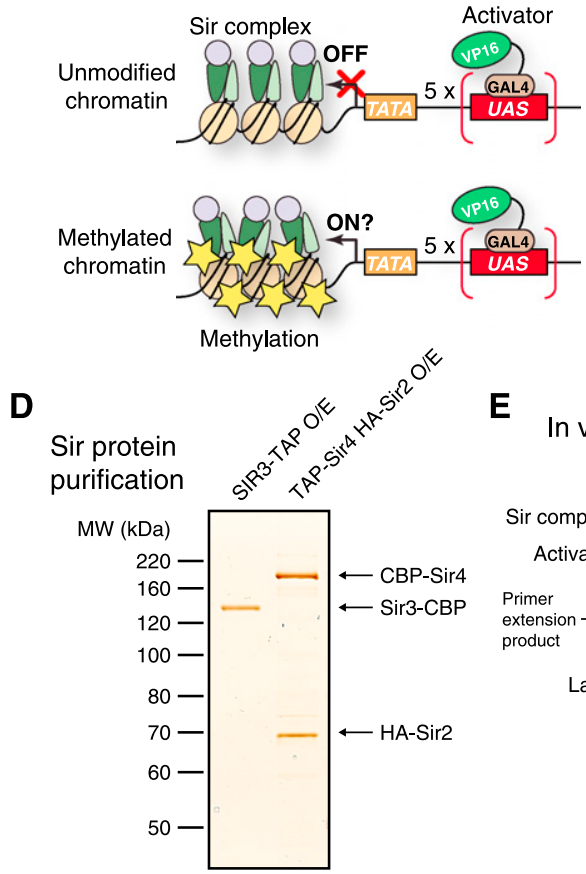

G Immobilized IVT Western blot

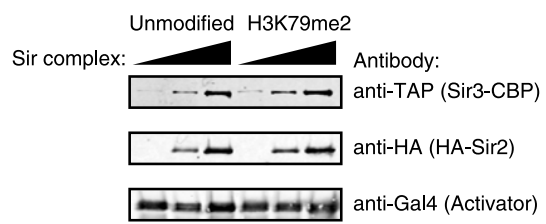

$\mathbf{H}$

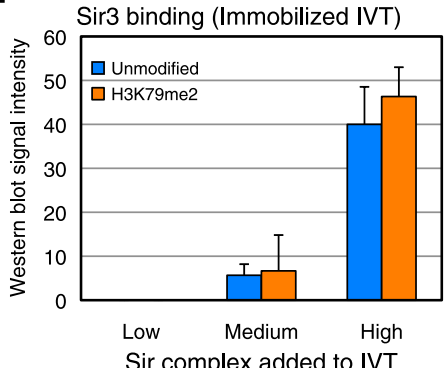
In vitro transcription strategy

Unmodified or methylated chromatin template

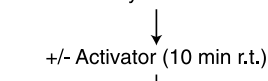

$+/$ Sir complex $\left(60 \min 30^{\circ} \mathrm{C}\right)$

Yeast nuclear extract (30 min r.t.)

Primer extension assay

E In vitro transcription
C

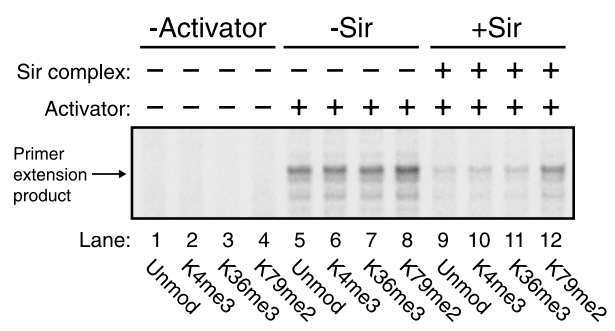

F

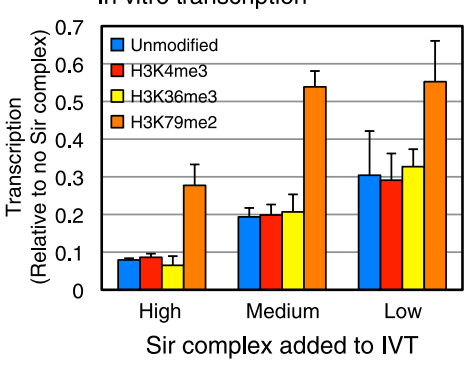

I

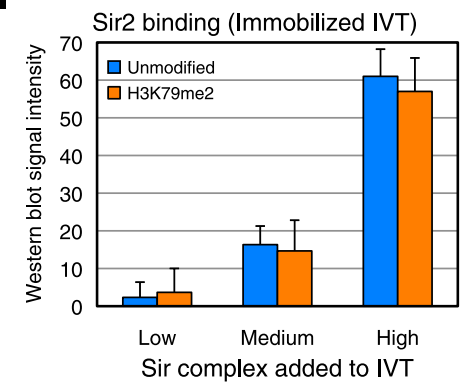

Figure 5. H3K79me disrupts gene silencing without affecting Sir complex binding in vitro. (A) Schematic of the chromatin template and protein components involved in the in vitro silencing assay. $(B)$ Outline of the in vitro silencing experiment. $(C)$ Western blot of the MLA nucleosomes used for chromatin assembly. Anti-H3K4me3, anti-H3K36me3, anti-H3K79me2, and anti-H3 antibodies were used. $(D)$ Silver-staining gel of the Sir proteins purified from yeast cells overexpressing Sir3-TAP or TAP-Sir4/HA-Sir2. (E) Representative phosphor screen image of a primer extension assay from the IVT experiment outlined in $B$. The signal represents the ${ }^{32} \mathrm{P}$ end-labeled cDNA product generated by primer extension. $(F)$ Quantification of phosphor screen images of the IVT experiments shown in E. Approximately 26 pmol of Sir3 and 8 pmol each of Sir2 and Sir4 were included in the reaction labeled "High." Reactions labeled "Medium" and "Low" contained, respectively, one-half and one-fourth the amount of Sir proteins relative to "High." Data are presented as mean \pm SD. $(G)$ Representative image of Sir protein binding from the immobilized IVT Western blot experiment. Anti-TAP, anti-HA, and anti-Gal4 antibodies were used. $(H, I)$ Quantification of the immobilized IVT Western blot experiment shown in $G$. The binding levels of Sir3 $(H)$ and Sir2 $(I)$ are presented as mean \pm SD. 
was first prebound to the chromatinized templates, and purified Sir proteins (Sir2/Sir3/Sir4), sufficient for silencing in vitro (Johnson et al. 2009), were added to the reactions. Sir proteins (Sir3-TAP and TAP-Sir4/HA-Sir2) were purified using a yeast overexpression system described previously by Moazed and colleagues (Johnson et al. 2009) (Fig. 5D). Yeast nuclear extract was added to the reaction following the binding of Sir proteins to the chromatinized template along with nucleoside triphosphates (NTPs), and transcription was measured by primer extension. An outline of this in vitro silencing experiment is depicted in Figure 5B.

As shown in Figure 5E, transcription was strongly dependent on Activator (lanes 1-8) and was reduced by the addition of Sir proteins to the reaction (lanes 5-12). However, strikingly, when the chromatin template was dimethylated at $\mathrm{H} 3 \mathrm{~K} 79$, silencing was strongly reduced compared with the template with no modifications (Fig. 5E, lanes 9-12). This effect was specific to H3K79me2, as neither H3K4me3 nor H3K36me3 was able to disrupt silencing (Fig. 5E, lanes 9-12). Transcription increased by approximately twofold to threefold on the H3K79me2 chromatin template compared with the unmodified template in the presence of Sir proteins (Fig. 5F). Therefore, since H3K79me is found at subtelomeric chromatin selectively in the ON state and its presence on chromatin is sufficient to disrupt Sir protein-mediated silencing in vitro, we conclude that $\mathrm{H} 3 \mathrm{~K} 79$ me plays a causal role in determining the natural epigenetic ON state.

We next sought to assess the amount of Sir protein binding to the unmodified and H3K79me2 chromatin templates during IVT. To accomplish this, we performed an IVT reaction in a manner similar to that used above but with biotinylated unmodified and H3K79me2 chromatin templates immobilized to streptavidin-coated magnetic beads (Lin and Carey 2012). The amount of Sir protein binding to the immobilized templates was determined by Western blot following IVT and washing (Fig. 5G). Critically, as quantified in Figure 5, H and I, binding of Sir3 and Sir2 did not differ between the unmodified and H3K79me2 templates. Similarly, we did not observe a significant difference in the binding of the Sir complex to the unmodified and H3K79me2 chromatin templates when the Sir complex-chromatin interaction was measured in the absence of Activator or yeast nuclear extract (Supplemental Fig. S5). We conclude that H3K79me2 can disrupt gene silencing without noticeably affecting the amount of binding of the Sir complex to nucleosomes in vitro.

The discrepancy between our results and those of a previous study in which H3K79me had been shown to block Sir complex binding to a chromatin template in vitro (Martino et al. 2009) may be due to differences in the experimental techniques used. While the previous study had used electrophoretic mobility shift assays (EMSAs) to determine the Sir complex-chromatin interaction (Martino et al. 2009), here we used an immobilized chromatin template assay to directly measure Sir protein binding by Western blot and showed that the amount of Sir complex bound to chromatin was largely not affected by H3K79me. In either case, methylation of H3K79 may disrupt the interaction between Sir3 and the region surrounding H3K79 (Altaf et al. 2007; Fingerman et al. 2007). We propose that this disruption alters the overall conformation of the Sir2/Sir3/Sir4-nucleosome complex and that this alteration in turn enables the epigenetic ON state.

\section{Maintenance of H3K79me is dependent on transcription in the epigenetic ON state}

As demonstrated above, the key difference between $\mathrm{ON}$ and OFF telomeres is the enrichment of H3K79me, which is capable of disrupting gene silencing. We next addressed how H3K79me is maintained epigenetically through multiple cell generations at the ON telomere. Since the H3K79 methyltransferase Dot1 is recruited to chromatin through transcription (Shahbazian et al. 2005; Millar and Grunstein 2006), we hypothesized that the maintenance of $\mathrm{H} 3 \mathrm{~K} 79 \mathrm{me}$ in the $\mathrm{ON}$ state may be dependent on transcription. To test this possibility, we asked whether $\mathrm{H} 3 \mathrm{~K} 79 \mathrm{me}$ at the $\mathrm{ON}$ telomere would be lost upon inhibition of transcription. We monitored the chromatin state of ADE2-TEL05R, whose ON state could be selected by growing cells in medium lacking adenine (SC-ade). As a control, we examined YFR057W at native TEL06R. Similar to the ON state of URA3-TEL07L, the ADE2-TEL05R ON state was accompanied by an increase in $\mathrm{H} 3 \mathrm{~K} 79$ me (Supplemental Fig. S6). After selecting for ADE2-TEL05R ON by growing cells in SC-ade, we specifically repressed $A D E 2$ through negative feedback by adding excess adenine to the medium. This treatment causes the dissociation of the activator Pho2 from the promoter of ADE2 (Fig. 6A; Pinson et al. 2009). The same method cannot be used for repression of URA3-TEL07L, since adding excess uracil to the medium would be toxic to the cells (Gadsden et al. 1993). As shown in Figure 6, B and $\mathrm{C}$, by qRT-PCR and RNAPII ChIP, ADE2 expression decreased rapidly to near-background level following adenine addition. In a corresponding manner, we found that H3K79me1 is gradually lost every cell cycle and eventually drops to near-background level (Fig. 6D; Supplemental Fig. S6). These results imply that a self-reinforcing feedback loop in which $\mathrm{H} 3 \mathrm{~K} 79$ me both results from and is causal for transcription maintains the epigenetic $\mathrm{ON}$ state of TPE.

\section{Discussion}

The mechanism of heterochromatin spreading and gene silencing at the telomeres of Saccharomyces cerevisiae has been characterized extensively (Rusche et al. 2003; Mondoux and Zakian 2006). However, how variegated gene expression occurs at telomeres has been unclear. To address this problem, we separated the natural $\mathrm{ON}$ and OFF cells from a population of yeast undergoing TPE and directly compared the chromatin structure of the natural ON state with that of the OFF state. This is unlike previous studies in which mixed ON and OFF telomeres were compared with the disrupted telomeres of sir 
A
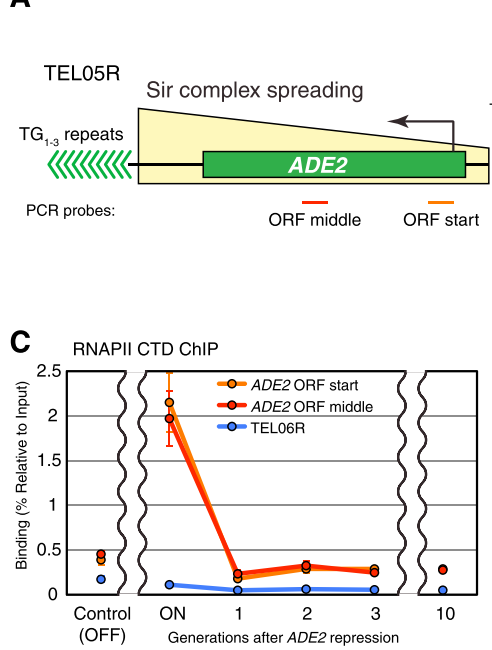
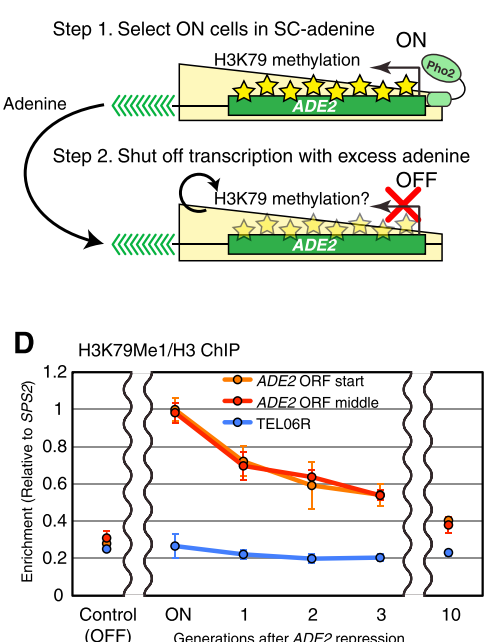

Figure 6. Maintenance of $\mathrm{H} 3 \mathrm{~K} 79 \mathrm{me}$ at the ON telomere depends on transcription. (A) Schematic of the ADE2 feedback repression experiment to monitor the level of histone methylation after inhibition of transcription. The ADE2 ORF middle and ORF start probes are $\sim 1.0$ and $2.0 \mathrm{~kb}$ away, respectively, from the telomeric repeats of $A D E 2-T E L 05 \mathrm{R}$. (B) qRT-PCR of ADE2 at TEL05R (red lines) and YFR057W at native TEL06R (blue lines) before and after the addition of adenine. A culture continuously grown in the presence of excess adenine ( $>30$ generations) was used as an OFF control. Data are presented as mean $\pm \mathrm{SD}$. $(C, D)$ ChIP of RNAPII $(C)$ and $\mathrm{H} 3 \mathrm{~K} 79 \mathrm{mel} / \mathrm{H} 3$ $(D)$ at $A D E 2-T E L 05 R$ and native TEL06R using the cultures described in $B$. The ADE2 ORF middle (red lines) and ORF start (orange lines) probes were as described in $A$. The native TEL06R (blue lines) probe is $\sim 1.5 \mathrm{~kb}$ away from the telomeric repeats. Data are presented as mean $\pm \mathrm{SD}$.

mutant strains, which made it impossible to characterize the natural ON state (Rusche et al. 2003). Our findings indicate that (1) the natural ON telomere is characterized by Sir complex binding to nucleosomes; (2) histone $\mathrm{H} 4 \mathrm{~K} 16$ is deacetylated at the ON telomere, which is consistent with the spreading of Sir3 through telomeric heterochromatin by its interaction with deacetylated H4K16; (3) H3K79 is methylated in the natural ON state and can disrupt silencing without affecting Sir complex binding in vitro; and (4) maintenance of H3K79me is dependent on a transcription-mediated positive feedback loop. Our results suggest that, since the ON telomere is characterized by Sir3 binding and H4K16 hypoacetylation, two factors that are normally associated with silencing, other factors must determine the ON state. We show that H3K79me is such a factor. This is in contrast to previous studies, which proposed that the variation in Sir complex binding to nucleosomes regulates TPE (Ng et al. 2003; Moazed 2011).

The deacetylation of H4K16, a major requirement of heterochromatin formation, in the ON state is of special interest. It argues that H4K16ac is not the determinant of epigenetic variegation. Thus, our study differentiates the function of two key histone modification marks at heterochromatin, where H4K16 deacetylation determines the distance of heterochromatin protein spreading from the telomere by virtue of its interaction with Sir3 (Johnson et al. 1990, 2009; Kimura et al. 2002; Suka et al. 2002; Liou et al. 2005; Onishi et al. 2007), and H3K79me regulates the actual ON/OFF expression state of a subtelomeric gene.

It had been proposed previously that $\mathrm{H} 3 \mathrm{~K} 79$ me may disrupt the binding of the Sir complex to nucleosomes based on pull-down assays that measured the binding of the Sir3 protein to a peptide containing the H3K79 region (Altaf et al. 2007; Fingerman et al. 2007). Subsequently, it had been shown that binding of the whole Sir complex to a trinucleosomal chromatin template is also affected by H3K79me using a gel shift assay (Martino et al. 2009). However, we showed in vivo by ChIP and in vitro using an immobilized template assay in the presence of yeast nuclear extract that the overall binding level of the Sir proteins to the nucleosome was not significantly disrupted by H3K79me. Therefore, we favor instead a model in which the methylation-dependent loss of the Sir3-H3K79 interaction leads to a conformational change in the structure of the Sir protein-nucleosome complex, which results in disrupted gene silencing.

H3K79me and its methyltransferase, Dot1, are conserved in many organisms, including fruit flies, mice, and humans (Nguyen and Zhang 2011). It has been shown that mutations in the fruit fly DOT1 homolog grappa disrupts Polycomb group-mediated silencing as well as telomeric silencing in flies (Shanower et al. 2005). Similarly, knockout of the mouse DOT1 homolog Dot1L leads to the loss of heterochromatin-associated marks such as $\mathrm{H} 3 \mathrm{~K} 9 \mathrm{me}$ from centromeric and telomeric heterochromatin in mouse embryonic stem (ES) cells (Jones et al. 2008). Thus, H3K79me and Dot1 are relevant to gene silencing and heterochromatin formation in organisms other than the budding yeast.

In contrast, there are no homologs of Dot 1 or detectable levels of H3K79me in the fission yeast Schizosaccharomyces pombe (Sinha et al. 2010). Thus, while gene expression at the heterochromatin of $S$. pombe is also known to be 
regulated epigenetically, the mechanism inevitably cannot involve H3K79me. Allshire and colleagues (Ekwall et al. 1997) have shown that transient treatment of $S$. pombe cells with an HDAC inhibitor leads to a heritable hyperacetylated chromatin state accompanied by the loss of gene silencing at centromeric heterochromatin. Likewise, Grewal and colleagues (Nakayama et al. 2000) have shown that expression of a gene at the partially compromised centromeric heterochromatin of $S$. pombe is associated with hyperacetylation and lack of heterochromatin protein Swi6/HP1 binding. The epigenetic inheritance of gene expression in these studies could be explained by a positive feedback loop involving histone acetylation and lack of heterochromatin-binding proteins. This is in stark contrast to our findings at the telomeric heterochromatin of $S$. cerevisiae, which show that neither H4K16ac nor binding of heterochromatin proteins is a key regulator of gene variegation.

Instead, a positive feedback loop mediated by transcription and $\mathrm{H} 3 \mathrm{~K} 79 \mathrm{me}$ is at the heart of our model regarding the mechanism of epigenetic variegation at $S$. cerevisiae telomeres, as described below (Fig. 7). In this model, the $\mathrm{ON}$ state is characterized by $\mathrm{H} 3 \mathrm{~K} 79 \mathrm{me}$. The maintenance of $\mathrm{H} 3 \mathrm{~K} 79 \mathrm{me}$ is dependent on transcription, which had previously been shown to recruit the histone H3 Lys79 methyltransferase Dot1 (Shahbazian et al. 2005). $\mathrm{H} 3 \mathrm{~K} 79 \mathrm{me}$ in turn disrupts the local interaction between Sir3 and the H3 core region surrounding Lys79 (Altaf et al. 2007; Fingerman et al. 2007). However, in contrast to previous models, the Sir complex as a whole can still spread along the subtelomere through its interaction with deacetylated H4K16. In this structure, the methylation of H3K79 enables PIC assembly and transcription, possibly by inducing a conformational change in the Sir proteinnucleosome complex, thus promoting a positive feedback loop. The possible absence of an H3K79 histone demethylase (Liang et al. 2007) may further enhance the stability of this continuous ON state. In contrast, the absence of transcription in the OFF state precludes Dot1 recruitment and ensures H3K79 hypomethylation. It had previously been shown that Sir3 binding to nucleosomes can prevent Dot 1 from methylating chromatin (Altaf et al. 2007; Fingerman et al. 2007). Therefore, the lack of Dot1
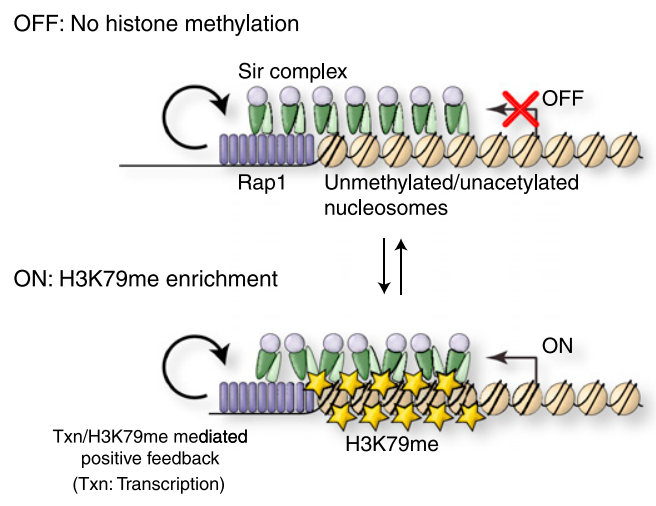

Figure 7. Model to explain the variegated gene expression pattern of TPE. See the text for details. recruitment and the prevention of Dot1 access to the H3K79 residue help establish a stable OFF state.

How is it then possible for a gene in one expression state to escape these feedback loops and convert to the other state? One possibility may be that changes in the length of telomeres (elongation/shortening) lead to the interconversion of epigenetic expression states. Previous studies from Lustig and colleagues (Kyrion et al. 1993; Park and Lustig 2000) have shown that elongated telomeres are associated with stronger subtelomeric gene silencing. Since the length of telomeres naturally fluctuates within a cell (Shore and Bianchi 2009), some telomeres may become abnormally shortened, and this may lead to a compromised heterochromatin structure susceptible to transcription. In contrast, abnormal lengthening may cause a structural change at an $\mathrm{ON}$ telomere that can overcome the anti-silencing effect of H3K79me and dampen gene expression until methylation is passively lost. In any case, whether the natural variation in telomere length is sufficient to induce epigenetic switching is still unknown. Changes in H3K79me are shown here to regulate the maintenance of the variegated $\mathrm{ON} / \mathrm{OFF}$ expression states at telomeric heterochromatin. However, the rare transient upstream events that initiate switching between the ON and OFF states remain to be observed and determined.

\section{Materials and methods}

Yeast strains, plasmids, and oligonucleotide probes

Yeast strains, plasmids, and oligonucleotide probes used in this study are listed in the Supplemental Material. Plasmid and PCR product-based genetic manipulations were performed using standard yeast transformation techniques (Gietz and Woods 2002). Full details are provided in the Supplemental Material.

\section{Protein purification}

Xenopus laevis histones and histone mutants (H3, H3C110AK4C, H3C110AK36C, H3C110AK79C, H4, H2A, and H2B) were purified as described previously (Luger et al. 1997). GAL4-VP16 was purified as described previously (Tantin et al. 1996). Sir proteins were purified as described previously (Tanny et al. 2004; Johnson et al. 2009) with some modifications to the protocol. Full details are provided in the Supplemental Material.

\section{MLA histone preparation}

H3K4me3, H3K36me3, and H3K79me2 MLA histones were generated from $\mathrm{H} 3 \mathrm{C} 110 \mathrm{AK} 4 \mathrm{C}, \mathrm{H} 3 \mathrm{C} 110 \mathrm{AK} 36 \mathrm{C}$, and $\mathrm{H} 3 \mathrm{C} 110 \mathrm{AK} 79 \mathrm{C}$ histone mutants, respectively, as described previously (Simon et al. 2007).

\section{$q R T-P C R$}

RNA was extracted using the hot acid phenol extraction method (Bookout et al. 2006). The extracted RNA samples were treated with DNase I (Qiagen), purified, and reverse-transcribed using random primers and M-MLV reverse transcriptase (Invitrogen). qPCR was performed and analyzed using the $\Delta \Delta \mathrm{Ct}$ method (Bookout et al. 2006). Full details are provided in the Supplemental Material. 


\section{Western blot}

Western blot assays were performed using the ODYSSEY infrared imaging system (LI-COR) following the manufacturer's protocol. Full details are provided in the Supplemental Material.

\section{ChIP}

Standard ChIP assays were performed as described previously (Hecht et al. 1996; Suka et al. 2001) with minor modifications to the protocol. Full details are provided in the Supplemental Material.

\section{Sequential ChIP}

Sequential ChIP was performed as described elsewhere (Kao et al. 2004) with minor modifications to the protocol. Briefly, chromatin lysate was immunoprecipitated overnight with antiFlag M2 agarose beads (Sigma-Aldrich). The agarose beads were washed, and the chromatin fragments were eluted off the beads with 3x Flag peptide (Sigma-Aldrich). Part of the eluate was saved and used as the input control DNA for the second (sequential) ChIP. Sequential ChIP assays were performed using the same protocol as standard ChIP. Full details are provided in the Supplemental Material.

\section{FACS-ChIP}

FACS was performed using BD FACSAria II (BD Biosciences) according to the manufacturer's manual. Full details are provided in the Supplemental Material.

\section{IVT/silencing}

IVT was performed as described previously (Lin and Carey 2012) with minor modifications to the protocol. The DNA template containing five Gal4 DNA-binding sites and an adenovirus E4 promoter (G5E4T) (Tantin et al. 1996) was assembled into chromatin by salt dilution as described previously (Steger et al. 1997). Following prebinding of GAL4-VP16 to the template, Sir proteins were added to the IVT reaction. Yeast nuclear extract, prepared as described previously (Rani et al. 2004), was added to the reaction, and primer extension was performed to measure the amount of transcription. Full details are provided in the Supplemental Material.

\section{Immobilized chromatin template}

The immobilized chromatin template assays were performed essentially as described previously (Lin and Carey 2012) with some modifications to the protocol. Buffer conditions and DNA/protein components were as described above for the IVT/silencing experiments except that GAL4-VP4, a variant of GAL4-VP16 containing four tandem repeats of the activation domain, was used (Ohashi et al. 1994). We confirmed that the results of the IVT/silencing experiments described above were reproducible when GAL4-VP4 was substituted for GAL4-VP16 in the reaction (data not shown). Briefly, biotinylated chromatin templates were immobilized on M280 streptavidin beads, and IVT reactions were incubated by rotation. The beads were washed twice with reaction buffer and eluted with Laemmli buffer. Western blot was performed as described above and quantified using ImageQuant TL software.

\section{Acknowledgments}

We thank the present and past members of the laboratories of M.G., M.C. (especially Lynn Lehmann for GAL4-VP16, Justin Lin for H3K4me3 octamer, and Jason Gehrke), and Siavash Kurdistani (especially Maria Vogelauer) for providing materials, valuable suggestions, and constructive criticisms during the course of this work. We also thank Daniel Gottschling, James Broach, Danesh Moazed, and Ivan Sadowski for plasmids, strains, and antibodies; Aaron Johnson for sharing his TAP-Sir4/HA-Sir2 purification protocol; Rachelle Crosbie for sharing her fluorescence microscope; and Jamie Marshall for microscopy advice. Flow cytometry was performed in the UCLA Jonsson Comprehensive Cancer Center (JCCC) and Center for AIDS Research Flow Cytometry Core Facility, which is supported by National Institutes of Health awards CA-16042 and AI-28697 and by the JCCC, the UCLA AIDS Institute, the David Geffen School of Medicine at UCLA, and the UCLA Chancellor's Office. T.K. was supported by a fellowship from the Nakajima Foundation. B.G.K. was supported by Ruth L. Kirschstein National Research Service Award GM007185. This work was supported by National Institutes of Health grants GM23674, GM42421 (to M.G.), GM074701, and GM085002 (to M.C).

\section{References}

Altaf M, Utley RT, Lacoste N, Tan S, Briggs SD, Cote J. 2007. Interplay of chromatin modifiers on a short basic patch of histone $\mathrm{H} 4$ tail defines the boundary of telomeric heterochromatin. Mol Cell 28: 1002-1014.

Armache KJ, Garlick JD, Canzio D, Narlikar GJ, Kingston RE. 2011. Structural basis of silencing: Sir3 BAH domain in complex with a nucleosome at $3.0 \AA$ resolution. Science 334: 977-982.

Boeke JD, Trueheart J, Natsoulis G, Fink GR. 1987. 5-Fluoroorotic acid as a selective agent in yeast molecular genetics. Methods Enzymol 154: 164-175.

Bookout AL, Cummins CL, Mangelsdorf DJ, Pesola JM, Kramer MF. 2006. High-throughput real-time quantitative reverse transcription PCR. Curr Protoc Mol Biol 73: 15.8.1-15.8.28.

Buchman AR, Kimmerly WJ, Rine J, Kornberg RD. 1988. Two DNA-binding factors recognize specific sequences at silencers, upstream activating sequences, autonomously replicating sequences, and telomeres in Saccharomyces cerevisiae. Mol Cell Biol 8: 210-225.

Chen L, Widom J. 2005. Mechanism of transcriptional silencing in yeast. Cell 120: 37-48.

Ehrentraut S, Hassler M, Oppikofer M, Kueng S, Weber JM, Mueller JW, Gasser SM, Ladurner AG, Ehrenhofer-Murray AE. 2011. Structural basis for the role of the Sir3 $\mathrm{AAA}^{+}$ domain in silencing: Interaction with Sir4 and unmethylated histone H3K79. Genes Dev 25: 1835-1846.

Ekwall K, Olsson T, Turner BM, Cranston G, Allshire RC. 1997. Transient inhibition of histone deacetylation alters the structural and functional imprint at fission yeast centromeres. Cell 91: 1021-1032.

Fingerman IM, Li HC, Briggs SD. 2007. A charge-based interaction between histone $\mathrm{H} 4$ and Dot 1 is required for H3K79 methylation and telomere silencing: Identification of a new trans-histone pathway. Genes Dev 21: 2018-2029.

Frederiks F, Tzouros M, Oudgenoeg G, van Welsem T, Fornerod M, Krijgsveld J, van Leeuwen F. 2008. Nonprocessive methylation by Dot 1 leads to functional redundancy of histone H3K79 methylation states. Nat Struct Mol Biol 15: 550-557.

Gadsden MH, McIntosh EM, Game JC, Wilson PJ, Haynes RH. 1993. dUTP pyrophosphatase is an essential enzyme in Saccharomyces cerevisiae. EMBO J 12: 4425-4431.

Gao L, Gross DS. 2008. Sir2 silences gene transcription by targeting the transition between RNA polymerase II initiation and elongation. Mol Cell Biol 28: 3979-3994. 
Gietz RD, Woods RA. 2002. Transformation of yeast by lithium acetate/single-stranded carrier DNA/polyethylene glycol method. Methods Enzymol 350: 87-96.

Girton JR, Johansen KM. 2008. Chromatin structure and the regulation of gene expression: The lessons of PEV in Drosophila. Adv Genet 61: 1-43.

Gottschling DE, Aparicio OM, Billington BL, Zakian VA. 1990. Position effect at $S$. cerevisiae telomeres: Reversible repression of Pol II transcription. Cell 63: 751-762.

Hahn S. 2004. Structure and mechanism of the RNA polymerase II transcription machinery. Nat Struct Mol Biol 11: 394-403.

Hecht A, Strahl-Bolsinger S, Grunstein M. 1996. Spreading of transcriptional repressor SIR3 from telomeric heterochromatin. Nature 383: 92-96.

Hoppe GJ, Tanny JC, Rudner AD, Gerber SA, Danaie S, Gygi SP, Moazed D. 2002. Steps in assembly of silent chromatin in yeast: Sir3-independent binding of a Sir2/Sir4 complex to silencers and role for Sir2-dependent deacetylation. Mol Cell Biol 22: 4167-4180.

Imai S, Armstrong CM, Kaeberlein M, Guarente L. 2000. Transcriptional silencing and longevity protein Sir2 is an NAD-dependent histone deacetylase. Nature 403: 795-800.

Johnson LM, Kayne PS, Kahn ES, Grunstein M. 1990. Genetic evidence for an interaction between SIR3 and histone $\mathrm{H} 4$ in the repression of the silent mating loci in Saccharomyces cerevisiae. Proc Natl Acad Sci 87: 6286-6290.

Johnson A, Li G, Sikorski TW, Buratowski S, Woodcock CL, Moazed D. 2009. Reconstitution of heterochromatin-dependent transcriptional gene silencing. Mol Cell 35: 769-781.

Jones B, Su H, Bhat A, Lei H, Bajko J, Hevi S, Baltus G, Kadam S, Zhai H, Valdez R, et al. 2008. The histone H3K79 methyltransferase Dot1L is essential for mammalian development and heterochromatin structure. PLoS Genet 4: e1000190. doi: 10.1371/journal.pgen.1000190.

Kao CF, Hillyer C, Tsukuda T, Henry K, Berger S, Osley MA. 2004. Rad6 plays a role in transcriptional activation through ubiquitylation of histone H2B. Genes Dev 18: 184-195.

Katan-Khaykovich Y, Struhl K. 2005. Heterochromatin formation involves changes in histone modifications over multiple cell generations. EMBO J 24: 2138-2149.

Kimura A, Umehara T, Horikoshi M. 2002. Chromosomal gradient of histone acetylation established by Sas2 $p$ and Sir2p functions as a shield against gene silencing. Nat Genet 32: $370-377$.

Kirchmaier AL, Rine J. 2006. Cell cycle requirements in assembling silent chromatin in Saccharomyces cerevisiae. Mol Cell Biol 26: 852-862.

Klein F, Laroche T, Cardenas ME, Hofmann JF, Schweizer D, Gasser SM. 1992. Localization of RAP1 and topoisomerase II in nuclei and meiotic chromosomes of yeast. I Biol Chem 117: 935-948.

Kostrewa D, Zeller ME, Armache KJ, Seizl M, Leike K, Thomm M, Cramer P. 2009. RNA polymerase II-TFIIB structure and mechanism of transcription initiation. Nature 462: 323-330.

Kyrion G, Liu K, Liu C, Lustig AJ. 1993. RAP1 and telomere structure regulate telomere position effects in Saccharomyces cerevisiae. Genes Dev 7: 1146-1159.

Landry J, Slama JT, Sternglanz R. 2000. Role of $\mathrm{NAD}^{+}$in the deacetylase activity of the SIR2-like proteins. Biochem Biophys Res Commun 278: 685-690.

Li B, Lustig AJ. 1996. A novel mechanism for telomere size control in Saccharomyces cerevisiae. Genes Dev 10: 13101326.

Liang G, Klose RJ, Gardner KE, Zhang Y. 2007. Yeast Jhd2p is a histone H3 Lys4 trimethyl demethylase. Nat Struct Mol Biol 14: 243-245.
Lin JJ, Carey M. 2012. In vitro transcription and immobilized template analysis of preinitiation complexes. Curr Protoc Mol Biol 97: 12.14.1-12.14.19.

Liou GG, Tanny JC, Kruger RG, Walz T, Moazed D. 2005. Assembly of the SIR complex and its regulation by O-acetylADP-ribose, a product of NAD-dependent histone deacetylation. Cell 121: 515-527.

Luger K, Rechsteiner TJ, Flaus AJ, Waye MM, Richmond TJ. 1997. Characterization of nucleosome core particles containing histone proteins made in bacteria. J Mol Biol 272: 301311.

Luo K, Vega-Palas MA, Grunstein M. 2002. Rap1-Sir4 binding independent of other $\mathrm{Sir}, \mathrm{yKu}$, or histone interactions initiates the assembly of telomeric heterochromatin in yeast. Genes Dev 16: 1528-1539.

Madhani HD. 2007. From a to $\alpha$ : Yeast as a model for cellular differentiation. Cold Spring Harbor Laboratory Press, Cold Spring Harbor, NY.

Martino F, Kueng S, Robinson P, Tsai-Pflugfelder M, van Leeuwen F, Ziegler M, Cubizolles F, Cockell MM, Rhodes D, Gasser SM. 2009. Reconstitution of yeast silent chromatin: Multiple contact sites and O-AADPR binding load SIR complexes onto nucleosomes in vitro. Mol Cell 33: 323-334.

Meneghini MD, Wu M, Madhani HD. 2003. Conserved histone variant H2A.Z protects euchromatin from the ectopic spread of silent heterochromatin. Cell 112: 725-736.

Millar CB, Grunstein M. 2006. Genome-wide patterns of histone modifications in yeast. Nat Rev Mol Cell Biol 7: 657666.

Mishra K, Shore D. 1999. Yeast Ku protein plays a direct role in telomeric silencing and counteracts inhibition by rif proteins. Curr Biol 9: 1123-1126.

Moazed D. 2011. Mechanisms for the inheritance of chromatin States. Cell 146: 510-518.

Moazed D, Kistler A, Axelrod A, Rine J, Johnson AD. 1997. Silent information regulator protein complexes in Saccharomyces cerevisiae: A SIR2/SIR4 complex and evidence for a regulatory domain in SIR4 that inhibits its interaction with SIR3. Proc Natl Acad Sci 94: 2186-2191.

Mondoux MA, Zakian VA. 2006. Telomere position effect: Silencing near the end. In Telomeres, Cold Spring Harbor Monograph Series 45 (ed. T de Lange et al.), pp. 261-316. Cold Spring Harbor Laboratory Press, Cold Spring Harbor, NY.

Moretti P, Freeman K, Coodly L, Shore D. 1994. Evidence that a complex of SIR proteins interacts with the silencer and telomere-binding protein RAP1. Genes Dev 8: 2257-2269.

Nakayama J, Klar AJ, Grewal SI. 2000. A chromodomain protein, Swi6, performs imprinting functions in fission yeast during mitosis and meiosis. Cell 101: 307-317.

$\mathrm{Ng} \mathrm{HH}$, Feng Q, Wang H, Erdjument-Bromage H, Tempst $\mathrm{P}$, Zhang Y, Struhl K. 2002. Lysine methylation within the globular domain of histone $\mathrm{H} 3$ by Dot1 is important for telomeric silencing and Sir protein association. Genes Dev 16: $1518-1527$.

$\mathrm{Ng} \mathrm{HH}$, Ciccone DN, Morshead KB, Oettinger MA, Struhl K. 2003. Lysine-79 of histone $\mathrm{H} 3$ is hypomethylated at silenced loci in yeast and mammalian cells: A potential mechanism for position-effect variegation. Proc Natl Acad Sci 100: 1820 1825.

Nguyen AT, Zhang Y. 2011. The diverse functions of Dot1 and H3K79 methylation. Genes Dev 25: 1345-1358.

Ohashi Y, Brickman JM, Furman E, Middleton B, Carey M. 1994. Modulating the potency of an activator in a yeast in vitro transcription system. Mol Cell Biol 14: 2731-2739. 
Onishi M, Liou GG, Buchberger JR, Walz T, Moazed D. 2007. Role of the conserved Sir3-BAH domain in nucleosome binding and silent chromatin assembly. Mol Cell 28: 10151028.

Osborne EA, Dudoit S, Rine J. 2009. The establishment of gene silencing at single-cell resolution. Nat Genet 41: 800-806.

Park Y, Lustig AJ. 2000. Telomere structure regulates the heritability of repressed subtelomeric chromatin in Saccharomyces cerevisiae. Genetics 154: 587-598.

Pinson B, Vaur S, Sagot I, Coulpier F, Lemoine S, DaignanFornier B. 2009. Metabolic intermediates selectively stimulate transcription factor interaction and modulate phosphate and purine pathways. Genes Dev 23: 1399-1407.

Pokholok DK, Harbison CT, Levine S, Cole M, Hannett NM, Lee TI, Bell GW, Walker K, Rolfe PA, Herbolsheimer E, et al. 2005. Genome-wide map of nucleosome acetylation and methylation in yeast. Cell 122: 517-527.

Ptashne M. 2002. Genes \& signals. CSHL Press, Cold Spring Harbor, NY.

Rani PG, Ranish JA, Hahn S. 2004. RNA polymerase II (Pol II)TFIIF and Pol II-mediator complexes: The major stable Pol II complexes and their activity in transcription initiation and reinitiation. Mol Cell Biol 24: 1709-1720.

Riggs AD, Martienssen RA, Russo VEA. 1996. Introduction. In Epigenetic mechanisms of gene regulation, Cold Spring Harbor Monograph Series 32 (ed. VEA Russo et al.), pp. 1-4. Cold Spring Harbor Laboratory Press, Cold Spring Harbor, NY.

Rossmann MP, Luo W, Tsaponina O, Chabes A, Stillman B. 2011. A common telomeric gene silencing assay is affected by nucleotide metabolism. Mol Cell 42: 127-136.

Rusche LN, Kirchmaier AL, Rine J. 2003. The establishment, inheritance, and function of silenced chromatin in Saccharomyces cerevisiae. Annu Rev Biochem 72: 481-516.

Sabourin M, Tuzon CT, Fisher TS, Zakian VA. 2007. A flexible protein linker improves the function of epitope-tagged proteins in Saccharomyces cerevisiae. Yeast 24: 39-45.

Santos-Rosa H, Bannister AJ, Dehe PM, Geli V, Kouzarides T. 2004. Methylation of $\mathrm{H} 3$ lysine 4 at euchromatin promotes Sir3p association with heterochromatin. I Biol Chem 279: 47506-47512.

Sekinger EA, Gross DS. 2001. Silenced chromatin is permissive to activator binding and PIC recruitment. Cell 105: 403-414.

Shahbazian MD, Zhang K, Grunstein M. 2005. Histone H2B ubiquitylation controls processive methylation but not monomethylation by Dot1 and Set1. Mol Cell 19: 271-277.

Shanower GA, Muller M, Blanton JL, Honti V, Gyurkovics H, Schedl P. 2005. Characterization of the grappa gene, the Drosophila histone H3 lysine 79 methyltransferase. Genetics 169: 173-184.

Shia WJ, Li B, Workman JL. 2006. SAS-mediated acetylation of histone H4 Lys 16 is required for H2A.Z incorporation at subtelomeric regions in Saccharomyces cerevisiae. Genes Dev 20: 2507-2512.

Shore D, Bianchi A. 2009. Telomere length regulation: Coupling DNA end processing to feedback regulation of telomerase. EMBO I 28: 2309-2322.

Simon MD, Chu F, Racki LR, de la Cruz CC, Burlingame AL, Panning B, Narlikar GJ, Shokat KM. 2007. The site-specific installation of methyl-lysine analogs into recombinant histones. Cell 128: 1003-1012.

Singer MS, Kahana A, Wolf AJ, Meisinger LL, Peterson SE, Goggin C, Mahowald M, Gottschling DE. 1998. Identification of high-copy disruptors of telomeric silencing in Saccharomyces cerevisiae. Genetics 150: 613-632.
Sinha I, Buchanan L, Ronnerblad M, Bonilla C, Durand-Dubief M, Shevchenko A, Grunstein M, Stewart AF, Ekwall K. 2010. Genome-wide mapping of histone modifications and mass spectrometry reveal $\mathrm{H} 4$ acetylation bias and H3K36 methylation at gene promoters in fission yeast. Epigenomics 2: 377-393.

Smith JS, Brachmann CB, Celic I, Kenna MA, Muhammad S, Starai VI, Avalos JL, Escalante-Semerena JC, Grubmeyer C, Wolberger C, et al. 2000. A phylogenetically conserved $\mathrm{NAD}^{+}$-dependent protein deacetylase activity in the Sir2 protein family. Proc Natl Acad Sci 97: 6658-6663.

Sperling AS, Grunstein M. 2009. Histone H3 N-terminus regulates higher order structure of yeast heterochromatin. Proc Natl Acad Sci 106: 13153-13159.

Steger DJ, Owen-Hughes T, John S, Workman JL. 1997. Analysis of transcription factor-mediated remodeling of nucleosomal arrays in a purified system. Methods 12: 276-285.

Strahl-Bolsinger S, Hecht A, Luo K, Grunstein M. 1997. SIR2 and SIR4 interactions differ in core and extended telomeric heterochromatin in yeast. Genes Dev 11: 83-93.

Suka N, Suka Y, Carmen AA, Wu J, Grunstein M. 2001. Highly specific antibodies determine histone acetylation site usage in yeast heterochromatin and euchromatin. Mol Cell 8: 473479.

Suka N, Luo K, Grunstein M. 2002. Sir2p and Sas2p opposingly regulate acetylation of yeast histone $\mathrm{H} 4$ lysine 16 and spreading of heterochromatin. Nat Genet 32: 378-383.

Takahashi YH, Schulze JM, Jackson J, Hentrich T, Seidel C, Jaspersen SL, Kobor MS, Shilatifard A. 2011. Dot1 and histone H3K79 methylation in natural telomeric and HM silencing. Mol Cell 42: 118-126.

Tanny JC, Kirkpatrick DS, Gerber SA, Gygi SP, Moazed D. 2004. Budding yeast silencing complexes and regulation of Sir2 activity by protein-protein interactions. Mol Cell Biol 24: 6931-6946.

Tantin D, Chi T, Hori R, Pyo S, Carey M. 1996. Biochemical mechanism of transcriptional activation by GAL4-VP16. Methods Enzymol 274: 133-149.

Tompa R, Madhani HD. 2007. Histone H3 lysine 36 methylation antagonizes silencing in Saccharomyces cerevisiae independently of the Rpd3S histone deacetylase complex. Genetics 175: 585-593.

van Leeuwen F, Gafken PR, Gottschling DE. 2002. Dot1p modulates silencing in yeast by methylation of the nucleosome core. Cell 109: 745-756.

Verzijlbergen KF, Faber AW, Stulemeijer IJ, van Leeuwen F. 2009. Multiple histone modifications in euchromatin promote heterochromatin formation by redundant mechanisms in Saccharomyces cerevisiae. BMC Mol Biol 10: 76. doi: 10.1186/1471-2199-10-76.

Xu EY, Zawadzki KA, Broach JR. 2006. Single-cell observations reveal intermediate transcriptional silencing states. Mol Cell 23: 219-229.

Xu F, Zhang Q, Zhang K, Xie W, Grunstein M. 2007. Sir2 deacetylates histone $\mathrm{H} 3$ lysine 56 to regulate telomeric heterochromatin structure in yeast. Mol Cell 27: 890-900.

Yang B, Britton J, Kirchmaier AL. 2008. Insights into the impact of histone acetylation and methylation on Sir protein recruitment, spreading, and silencing in Saccharomyces cerevisiae. J Mol Biol 381: 826-844. 


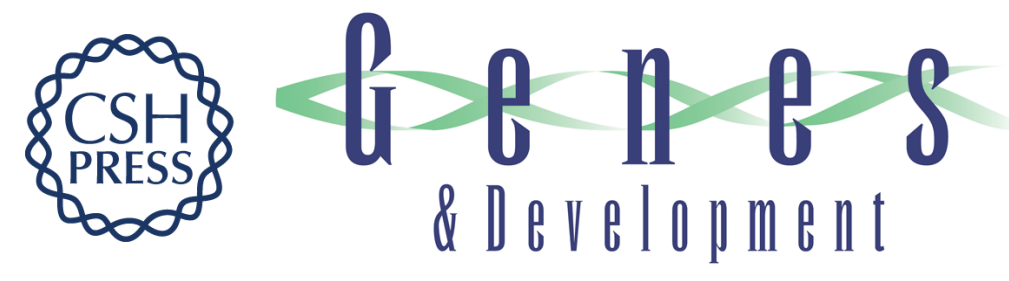

\section{Mechanism for epigenetic variegation of gene expression at yeast telomeric heterochromatin}

Tasuku Kitada, Benjamin G. Kuryan, Nancy Nga Huynh Tran, et al.

Genes Dev. 2012, 26:

Access the most recent version at doi:10.1101/gad.201095.112

\section{Supplemental http://genesdev.cshlp.org/content/suppl/2012/12/13/26.21.2443.DC1 Material}

References This article cites 81 articles, 27 of which can be accessed free at: http://genesdev.cshlp.org/content/26/21/2443.full.html\#ref-list-1

\section{License}

Email Alerting

Service

Receive free email alerts when new articles cite this article - sign up in the box at the top right corner of the article or click here.

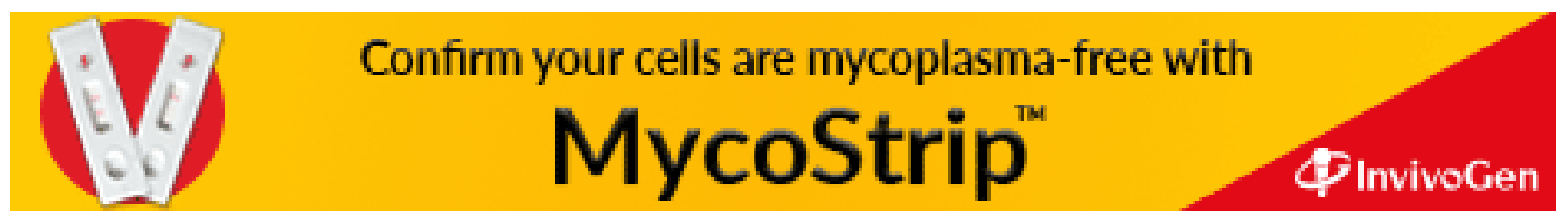

